
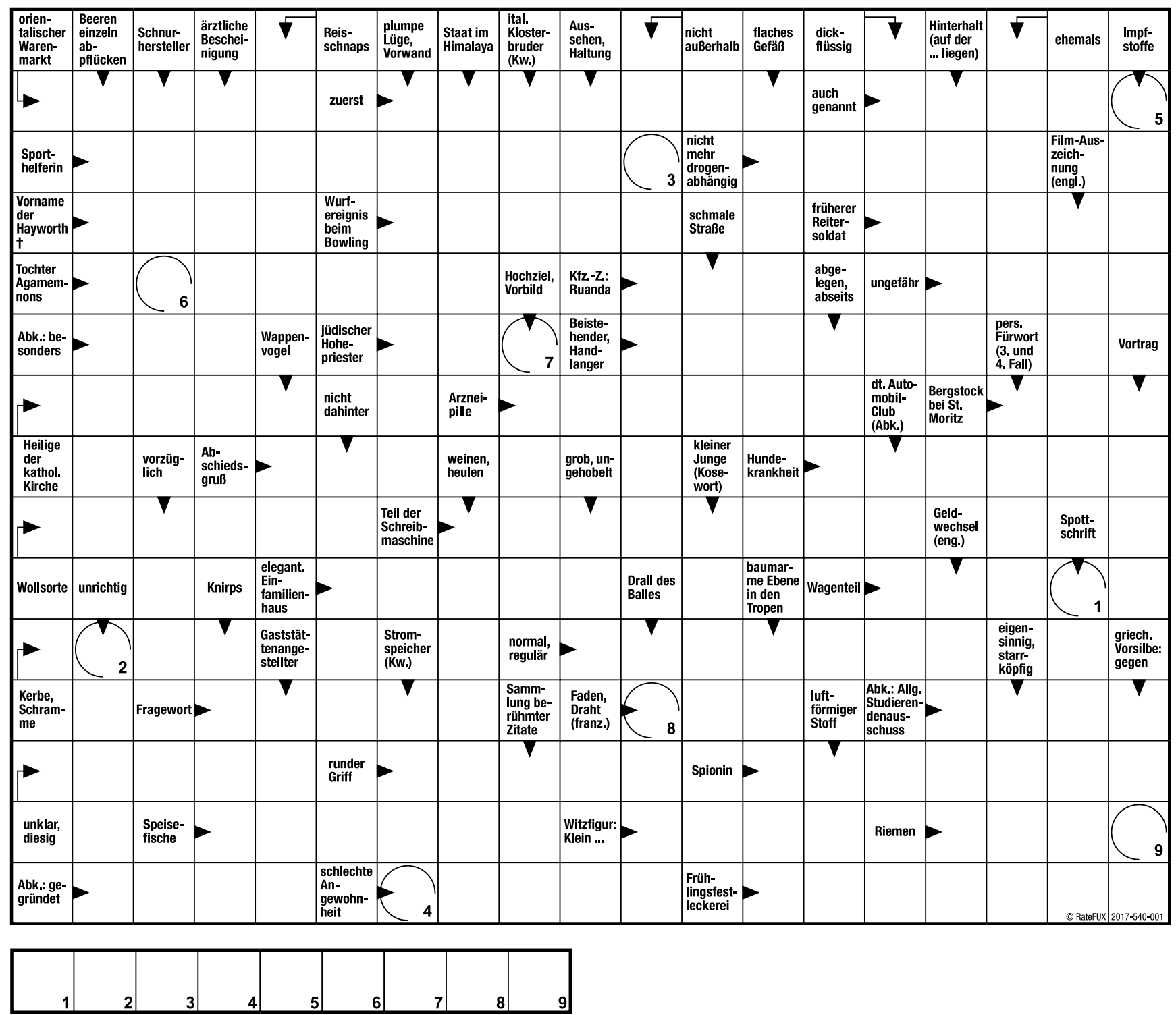

\title{
Angebohrt
}

\section{Fossiler Zahnwechsel}

Ein Tyrannosaurus Rex müsste man sein, könnte so mancher Patient beim Verlust seiner Zähne denken. Die insgesamt 60 Zähne von T. rex bestanden zwar anscheinend wie beim Menschen aus Schmelz, Dentin und Zahnbein, der entscheidende Unterschied: Der Fleischfresser wechselte die Beißer aber einfach spätestens alle eineinhalb Jahre aus.

Forscher im Berliner Naturkundemuseum untersuchen derzeit das Gebiss von „Tristan“, einem der drei besterhaltenen Skelette eines Tyrannosaurus Rex weltweit: Riss „Tristan“ mit der Kraft von bis zu fünf Tonnen seine Beute, brach schon auch mal ein Zahn ab. Kein Problem, denn es wuchs einfach ein neuer Zahn nach. Bei den Vegetariern unter den Sauriern wurden die Zähne übrigens so stark abgenutzt, dass die Zähne sogar jedes halbe bis Dreivierteljahr nachwuchsen.
(Kein) Namenswechsel

Ausgefallene, „sprechende“ Familiennamen sind mal Segen, mal Bürde, bieten Anlass zu Spott oder zu interessierten Nachfragen.

Peter Nachtweh etwa ist Zahnarzt in Berlin. Patienten spielen immer wieder gerne auf den Zusammenhang zwischen seinem Nachnamen und seinem Beruf an. Auf seiner Praxis-Homepage klärt Nachtweh deshalb auf, sein Famlienname habe nichts mit nächtlichen Schmerzen zu tun, sondern gehe auf die alte Berufsbezeichnung für den „Nachtweider“, also einen Gemeindehirten, zurück. Kein Grund also für eine Namensänderung. Einer seiner Assistenten hat aber irgendwann tatsächlich seinen Nachnamen ändern lassen. Der Name des jungen Zahnarztes ließ wohl nur wenige Patienten schmunzeln: Er hieß „Kummer“.

mar 